\title{
Validation using Nucleic Acid Testing (NAT) on Blood Donor Samples Non-Reactive to Transfusion-Transmissible Viruses by Immunoassay (EIA/ChLIA)
}

Rhoda Yu, ${ }^{1}$ Iza Mae Chamen, ${ }^{1}$ Kenneth Aristotle Punzalan, ${ }^{1}$ Benjamin de Vera III, ${ }^{1}$ Elizabeth Arcellana-Nuqui ${ }^{2}$

${ }^{1}$ Research Institute for Tropical Medicine - Department of Health, Philippines

${ }^{2}$ The Medical City, Ortigas Avenue, Pasig City, Philippines

\section{ABSTRACT}

Transfusion-transmissible infections (HIV, HBV and HCV) remain a threat to public health specifically in assuring safe transfusion practices. This study aims to determine the ability of a blood service facility to accurately detect HIV, Hepatitis B and C and assess the need to include nucleic acid testing as part of the routine screening algorithm. Of the 3,233 samples from participants with screened sero-negative blood units, testing for HIV and Hepatitis C showed no discrepancies with EIA and NAT in all samples. Testing for Hepatitis B showed $12(4.00 \%)$ samples which are reactive in both EIA and NAT, $3(0.09 \%)$ samples were reactive with EIA only and 48 (1.48\%) were detected for the presence of Hepatitis B Virus via NAT.

Key words: blood transfusions, human immunodeficiency virus, hepatitis, transfusion transmissible infections, nucleic acid test

ISSN 0118-3265

Printed in the Philippines.

Copyright@ 2017 by the PJP.

Received: 15 November 2016.

Accepted: 15 December 2016.

Published online first: 20 December 2016.

https://doi.org/10.21141/PJP.2017.008

Corresponding author: Kenneth Aristotle P. Punzalan, RMT

E-mail: kenn.punzalan@gmail.com

\section{INTRODUCTION}

Transfusion-transmissible infections (HIV, $\mathrm{HBV}$ and $\mathrm{HCV}$ ) remain a threat to public health specifically in assuring safe transfusion practices. Although constant efforts are being exerted to eliminate possible transfusion of undetected infected blood products, there is still a certain level of residual risk that threatens blood safety.

Majority of blood service facilities in the Philippines are limited to the use of serological tests to detect antigen and antibodies which are less sensitive than the nucleic acid screening tests (NAT). A study by Lam et al., reported that upon retesting of 449 screened nonreactive blood units with nucleic acid testing, $0.45 \%$ were missed using serological tests alone. ${ }^{1}$

This study aims to determine the ability of a blood service facility to accurately detect HIV, Hepatitis B and C and assess the need to include nucleic acid testing as part of the routine screening algorithm.

\section{METHODOLOGY}

\section{Participants}

A total of 32 lead blood service facilities that had a monthly blood collection of more than 500 and participates in the TTI Serology External Quality Assessment Scheme was identified to participate in this study by the technical working group of the National Council for Blood Services (NCBS-TWG) through purposive sampling design. A department circular with written instructions and disclosure of the study design was disseminated to the identified facilities. Only 15 facilities from Luzon (60\%), Visayas (26.67\%) and Mindanao (13.33\%) participated in the study. ${ }^{2}$

\section{Sampling}

Five percent of the monthly blood collection that have been tested non-reactive by serology tests and ready for transfusion were randomly selected by the participants and sent to the TTI-NRL for a period of 6 months. 


\section{Testing}

Samples received were transferred to a sterile cryotubes and were tested using the Roche cobas s201 MPX v2.0 in pools of 6. NATnegative results were reported and NAT-detected results were tested using the same platform in pools of 1. Results for pools of 1 were reported. The samples were then tested with Bio-Rad Genscreen $^{\mathrm{TM}}$ ULTRA HIV Ag-Ab, Monolisa ${ }^{\mathrm{TM}}$ ULTRA HBsAg, Monolisa $^{\mathrm{TM}}$ HCV Ag-Ab ULTRA using the Bio-Rad Evolis ${ }^{\mathrm{TM}}$ automated enzyme immunoassay (EIA) processor. Non-reactive results were reported and reactive results were retested using the modular method (Figure 1).

\section{Limitations}

Samples were sent in frozen aliquots by the participants following proper referral guidelines. Although detailed instructions were sent to participants in terms of preparation and transport of sample, blood cold chain practices of blood service facilities vary. Supplies for collection and referral were not provided by the TTI-NRL but were shouldered by the participants. The participants were instructed to randomly pick $5 \%$ of their sample for every test run for a period of 6 months, no specific instructions were given as to ensure that random sampling was properly done.

\section{RESULTS AND DISCUSSION}

Of the 3,233 samples from participants with screened sero-negative blood units, testing for HIV and Hepatitis C showed no discrepancies with EIA and NAT in all samples. Testing for Hepatitis B showed $12(4.00 \%)$ samples which are reactive in both EIA and NAT, 3 $(0.09 \%)$ samples were reactive with EIA only and $48(1.48 \%)$ were detected for the presence of Hepatitis B Virus via NAT (Table 1).

\begin{tabular}{lcrrrrr} 
Table 1. Hepatitis B testing results \\
\cline { 2 - 8 } & \multicolumn{2}{c}{ NAT (+) } & \multicolumn{2}{c}{ NAT (-) } & \multicolumn{2}{c}{ TOTAL } \\
\cline { 2 - 8 } & \multicolumn{1}{c}{ No. } & \multicolumn{1}{c}{ No. } & \multicolumn{1}{c}{ No. } & \multicolumn{1}{c}{$\%$} \\
\hline EIA (+) & 12 & 4 & 3 & 0.09 & 15 & 0.46 \\
EIA (-) & 48 & 1.48 & 3170 & 98.50 & 3218 & 99.54 \\
TOTAL & 60 & 1.85 & 3173 & 98.14 & 3233 & 100.00 \\
\hline
\end{tabular}

The twelve Hepatitis B EIA and NAT reactive samples may have been either due to technical errors on the part of the testing facility or the platform used was not sensitive enough to detect the virus or viral mutants. A study by Scheiblauer et al., showed that some EIA assay kits missed HBsAg mutants and showed reduced sensitivity on certain genotypes. ${ }^{3}$ The three Hepatitis B EIA reactive and NAT

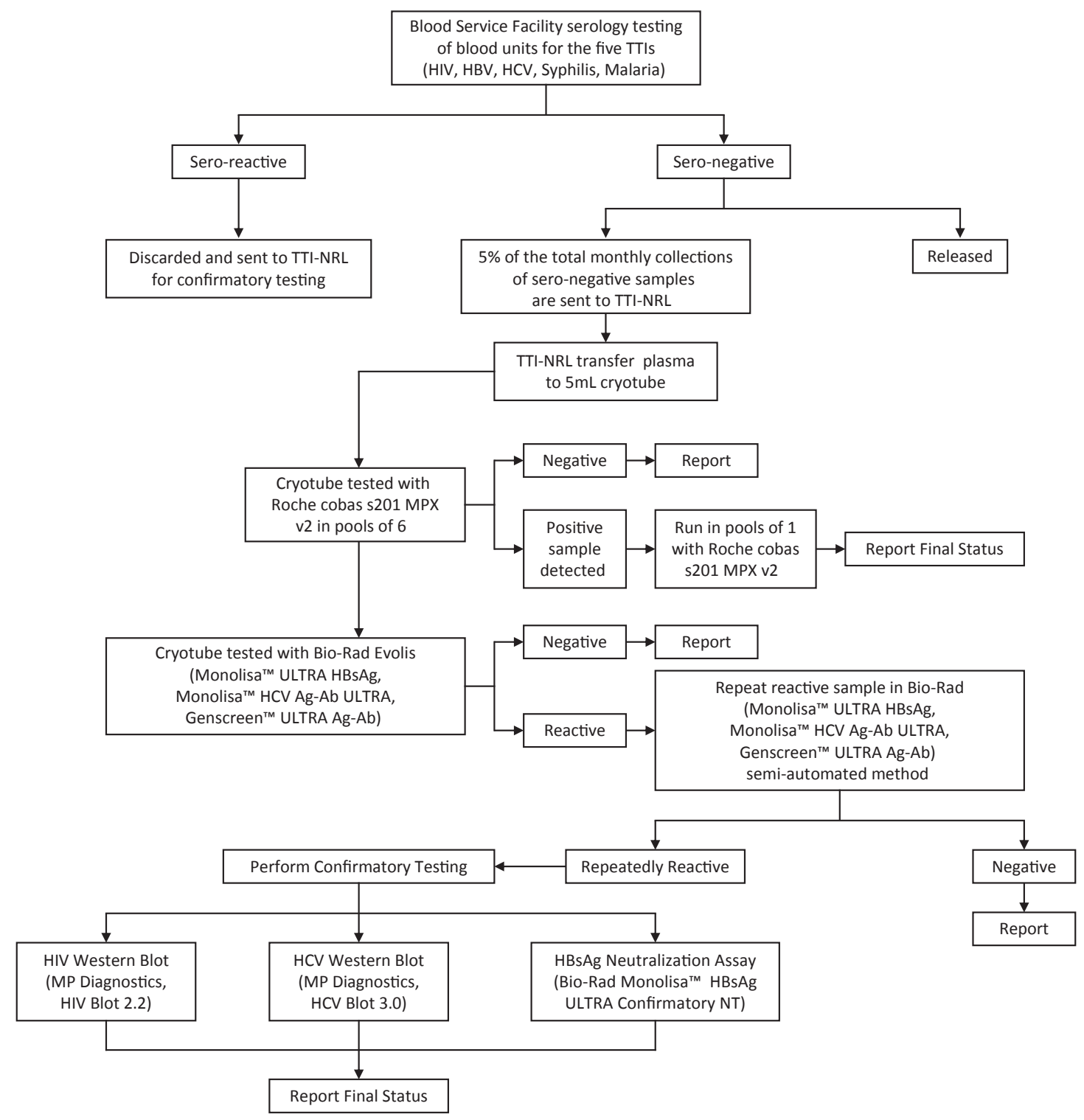

Figure 1. Testing process. 
negative may be due to low viremia or the inactive carrier status of the donor. ${ }^{4}$ The Hepatitis $\mathrm{B}$ discrepancy of 48 samples can be associated with the possibility of Hepatitis B viral mutants or occult blood infections (OBI) in which the presence of Hepatitis B Surface Antigen (HBsAg) in serological tests go undetected. This can be linked to the high prevalence of Hepatitis B infection in the country in which around 7.3 million Filipinos are chronically infected. ${ }^{5}$

\section{CONCLUSION}

NAT has been scientifically proven to reduce diagnostic window periods, and significantly decrease the residual risk of transfusion infection. ${ }^{6}$ Blood donor testing in the Philippines is limited to the detection of HBsAg and in addition to serological testing, NAT can play a vital role in assuring that the risk of transfusion infected blood is significantly lowered specially in cases of OBI. ${ }^{7}$ A study by Chigurapati et al., found that the combined yield (seronegative/ NAT reactive) for HIV-1, HCV, and HBV was 4 out of the 8,000 samples tested $(0.05 \%)$ and included only HBV. ${ }^{8}$

Discrepancies in the result of the BSF and the NRL may imply that quality systems in the BSF must be checked and validated.

\section{RECOMMENDATIONS}

All reactive results in the study will be subjected to further testing with HBV Monoplex RT PCR to replicate the results of Multiplex NAT and also for possible presence of anti-HBc and anti-HBs to determine cases of occult blood infection.

The use of NAT in the Philippines may be considered to be part of the national routine blood screening algorithm. Since NAT is highly expensive, a cost-benefit analysis for use of NAT may be done. Centralized testing on a national level may offer a more cost effective strategy as the high volume of units to be tested may impel suppliers to lower down costing. This approach however must be carefully planned since the geography of the country can be challenging and a feasibility study be conducted to ensure that hospitals requiring blood units are given stocks appropriately. Also, an alternative such as the addition of another serological marker (i.e. anti-HBc) may be considered. ${ }^{9}$ Validation of screened nonreactive blood units may be part of the routine process in referrals as part of the quality assurance in the national blood program.

The NRL also recommends that all BSFs establish and practice strict Quality Assurance Activities in Blood Screening. Realizing the current limitation in testing, there is a need for a paradigm shift in assuring blood safety. The safety of the blood supply does not depend on the strength of the testing platform but on the quality of blood donors. Blood donor recruitment and donor selection should be strengthened among all blood service facilities.

\section{ACKNOWLEDGMENTS}

The authors thank the TTI-NRL staff, Dr. Catherine Masangkay, Dr. Marilla Lucero and Dr. Socorro Lupisan of the Research
Institute for Tropical Medicine (RITM), the Health Facility Development Bureau, the Department of Health-National Voluntary Blood Services Program, and the National Council for Blood Services-Technical Working Group.

The authors also thank all the participating Blood Service Facilities for their cooperation.

\section{AUTHOR DISCLOSURE}

The authors declared no conflicts of interest.

\section{FUNDING SOURCE}

None.

\section{REFERENCES}

1. Lam HY, Belizario VY, Juban NR, Alejandria MM, Castillo-Carandang N, Arcellana-Nuqui E, Mirasol MA, et al. Assessing the residual risk for transfusion-transmitted infections in the Philippine blood supply. Yale J Biol Med. 2014;87(3):299-306. PMCID: PMC4144284.

2. Department of Health. Negative validation study for transfusion-transmissible infections in selected government and Philippine Red Cross Blood Service Facilities in the country. Manila, Philippines: Department Circular No. 2014-0032.

3. Scheiblauer H, El-Nageh M, Diaz S, Nick S, Zeichhardt H, Grunert HP, et al. Performance evaluation of 70 hepatitis B virus (HBV) surface antigen (HBsAg) assays from around the world by a geographically diverse panel with an array of $\mathrm{HBV}$ genotypes and HBsAg subtypes. Vox Sanguinis. 2009;98(3p2):403-14. https://doi.org/10.1111/j.1423-0410.2009.01272.x.

4. Sharma SK, Saini N, Chwla Y. Hepatitis B virus: inactive carriers. Virol J. 2005;2:82. https://doi.org/10.1186/1743422X-2-82.

5. Wong SN, Ong JP, Labio ME, Cabahug OT, Daez ML, Valdellon EV, ey al. Hepatitis B infection among adults in the Philippines: a national seroprevalence study. World J Hepatol. 2013;5(4):214-9. https://doi.org/10.4254/wjh.v5.i4. 214.PMID: 23671726 PMCID: PMC3648653.

6. Duncan R, Kourout M, Grigorenko E, Fisher C, Dong M. Advances in multiplex nucleic acid diagnostics for bloodborne pathogens: promises and pitfalls. Expert Rev Mol Diagn. 2016;16(1). https://doi.org/10.1586/14737159.2016.1112272.

7. Pourazar A, Salehi M, Jafarzadeh A, Arababadi MK, Oreizi F, Shariatinezhad K. Detection of HBV DNA in HBsAg negative normal blood donors. IJI. 2005;2(3):172-6.

8. Chigurapati P, Srinivasa Murthy K, Automated nucleic acid amplification testing in blood banks: an additional layer of blood safety. Asian J Transfus Sci. 2015;9(1):9-11. PMCID: PMC4339944. https://doi.org/10.4103/0973-6247.150938.

9. Kumar H, Gupta PK, Jaiprakash M. The role of anti-HBc IgM in screening of blood donors. Med J Armed Forces India. 2007;63(4):350-2. https://doi.org/10.1016/S0377-1237 (07)80013-X.

Disclaimer: This journal is OPEN ACCESS, providing immediate access to its content on the principle that making research freely available to the public supports a greater global exchange of knowledge. As a requirement for submission to the PJP, all authors have accomplished an AUTHOR FORM, which declares that the ICMJE criteria for authorship have been met by each author listed, that the article represents original material, has not been published, accepted for publication in other journals, or concurrently submitted to other journals, and that all funding and conflicts of interest have been declared. Consent forms have been secured for the publication of information about patients or cases; otherwise, authors have declared that all means have been exhausted for securing consent. 